Geront. clin. 1972;14:321

\title{
Architecture and the Elderly
}

The cost to the State of a long-stay elderly patient whose expectation of life may be as long as 3 years will vary depending on the hospital -between US-\$2,000 and 8,000.

W. Fine in his paper on Geriatric Ergonomics states that much unnecessary hospitalisation is caused by an unwise housing policy or by upgrading old houses with the aid of 'Development Grants' which allow in the UK amongst other things the construction of a toilet upstairs with the demolition of a downstairs toilet.

Most Geriatricians will agree that architects and town planners appear to plan mainly for the early decades of life and are apparently ignorant of the fact that by 1980 one in four of the population are expected to be over 65 and many of them suffer from locomotor handicaps. Even the planning of many geriatric wards is unsatisfactory. Their design prevents adequate observation of efficient use of nursing staff. As a result, unnecessary accidents to elderly patients may be caused. There is an urgent need to form sub-committees composed of geriatricians and General Practitioners interested in this subject of hospital building and town planning in different countries. These sub-committees should be attached to an appropriate Ministerial Department responsible for new town developments and hospital building.

The financial cost of the unnecessary hospitalisation of elderly citizens owing to an unfavourable environment is potentially enormous. The cost in human suffering when elderly patients are permanently imprisoned in institutions as a result of unwise planning or architecture, is of even greater significance than the financial cost.

E. Woodford-Williams 